Discourse and Communication for Sustainable Education, vol. 12, no. 2, pp. 45-53, 2021

\title{
Teachers' Perceptions on Code-Switching in EFL Classroom Discourse
}

\author{
Alireza Bonyadi and Mehdi Kheyrollahi Kalvanagh \\ Islamic Azad University, Urmia, Iran \\ Minoo Bonyadi \\ Allameh Tabataba'i University, Tehran, Iran
}

\begin{abstract}
Feasibility of maintaining an educational sustainable development (ESD) depends on exploring teachers' concepts on their common practices in classroom settings. Speakers in multilingual contexts commonly switch their codes, languages, during their numerous social interactions. Nowadays, the phenomena, code switching, has expanded to cover any situation in which speakers switch from one accepted code into another. Through this perspective, various studies have been conducted to investigate different aspects of code-switching in EFL classrooms. The present study qualitatively investigated teachers' perceptions on code-switching in their classrooms addressing two research questions, namely what types of code-switching EFL teachers were practicing in EFL classrooms and what were their perceptions on their code-switching. Four EFL teachers participated in the study. The analysis of the data collected through manual and electronic observations as well as structured interviews, indicated that intra-sentential and inter-sentential types of code-switching were practised throughout the classroom teaching processes. The main motives for resorting to code-switching were found to be EFL students' lack of linguistic proficiency, keeping solidarity with the students and managing the classrooms.
\end{abstract}

Key words: code-mixing, introspective data collection, multilingualism, solidarity, sociolinguistics

\section{Introduction}

Exploring EFL teachers' concepts and behavior is of importance in enhancing educational sustainable development, ESD, and quality education (Jodoin \& Singer, 2020; Heasly et al., 2020; Salite et al., 2009). However, there is insufficient research addressing ESD-related issues in EFL (Kapranov, 2021). The multicultural context of a society can undoubtedly influences the linguistic behavior of the individuals. The speech in this context might potentially take different forms that are referred to as codes (Wardhaugh, 2010). Code-switching, thus, has been defined as the substitution of one 
code with another, both intentionally and unintentionally. It is in fact "a conversational strategy used to establish, cross or destroy group boundaries; to create, evoke or change interpersonal relations with their rights and obligations" (Gal, 1988, p. 247). Besides meeting communication demands, code-switching also represents social function of language (Bhatti, 2018; Alhourani, 2018).

The term 'code-switching' has been used as a general term throughout the present paper, however, "some scholars have used the term code-switching when describing alternation between larger units, like clauses, and code-mixing when discussing alternation internal to the utterance or clause" (Muysken, 2011, p. 304). From a grammatical point of view, code-switching has been classified as: 1) 'Inter-sentential' that occurs between two separate utterances or two coordinated clauses belonging to the same utterance, 2) 'Extra-sentential/emblematic/tag' that occurs between a clause and an extra-clausal element attached to it, 3) 'Intra-sentential' that occurs within the clause, 4) 'Single word' as a subcategory of intra-clausal, and 5) 'Word internal' as the internally switched word forms a collocation with the next element (Muysken, 2011). However, for Wardhaugh, (2010) code-switching (also called code-mixing) can occur in conversation between speakers' turns or within a single speaker's turn. In the latter case, it can occur within a single sentence (intra-sententially) or between sentences (intersententially).

\section{Related Studies on Code-Switching}

Some studies have already been conducted on classroom code-switching. These studies considered code-switching as an effective classroom strategy' (Ahmad, 2009; Promnath, 2016) even if it has been considered as a useful teaching tool in EFL classrooms facilitating teaching and learning (Bista, 2010; Bhatti, 2018). Some researchers investigated the effect of code-switching on specific linguistic skills of the students. Yeganepoor (2013) reported that code-switching improved bilingual EFL learners' reading comprehension pointing out that mere exclusion of code-switching from the language classroom would not enhance the learning process. He, furthermore, argued that a positive or negative role of classroom code-switching called for extensive empirical research. In another investigation Nabifar (2017) argued that teachers' code-switching had a positive effect on learning problematic grammatical structures.

Other studies aimed at discovering the relationship between code-switching and the proficiency level of the teachers or students. Moghadam (2016) reported that the higher Iranian EFL teachers' educational level, the more they use code-switching in the classroom. Then and Ting (2009) declared that in circumstances where students' proficiency in the instructional language is not sufficient enough, code-switching would be a necessary tool for teachers to get their messages across effectively to the students. Songxaba (2017) reported a gradual move from a high tolerance of code-switching in lower levels to a low tolerance of code-switching in higher levels.

A brief review of literature indicated that since 2009 , lots of studies have been conducted on the issue of code-switching nationally and internationally. National studies focused on various issues such as code-switching functions, relationship between university professors' code-switching and their characteristics like their age and gender and the impact of code-switching on acquisition of different skills like reading compre- 
hension or learning grammatical structures. However, international studies were conducted to investigate different issues, namely learners' attitudes to their teachers' codeswitching, effects of teachers' code-switching on students' proficiency, different factors that affect code-switching and the functions of code-switching. As one can observe, to the best knowledge of the researchers, no comprehensive qualitative study has been carried out on teachers' perceptions on their code-switching. Thus, paving the way for a sustainable development in educational context (Zygmunt, 2016), and recognition the role of education and learning in the global quest for educational sustainability (Manteaw, 2020), the present study, in particular, aimed at addressing the following research questions:

RQ1 - What types of code-switching do EFL teachers practice in EFL classrooms?

RQ2 - What are EFL teachers' perceptions on their code-switching in EFL classrooms?

\section{Methodology}

Qualitative research methodology has been employed to address the research questions, namely what types of code-switching do EFL teachers practice? and what are their perceptions on their own code-switching in EFL classrooms?

Manual observations, electronic observations followed by stimulated recalls and then structured interviews with participants have been employed as three types of introspective data collection. (Nunan, 2009). In particular, observational protocol and classroom video-recordings have been used as the required instruments for addressing the first research question. In order to answer the second question, introspective data collection methods have been used: the method in which data collection happens at the same time as or very shortly after the events being investigated (Nunan, 2009, p. 285).

The research was carried out in an EFL language teaching institute in Urmia, working under the license of Ministry of Education of Iran. All the classrooms were equipped with multimedia devices. Four teachers were selected as participants of the study whose bio data are briefly presented as follow:

- Teacher B., 34 years old, holding an MA degree in English Translation Studies with 4 years of teaching experience.

- Teacher CH., 21 years old, holding a BA degree in English Language Teaching with 3 years of teaching experience.

- Teacher S., 32 years old, holding a BA degree in English Translation Studies with 4 years of teaching experience.

- Teacher T., 29 years old, busy doing his MA in English Language Teaching with 3 years of teaching experience.

In an effort to note down the possible instances of teachers' code-switching practices, four sessions of classroom observations were carried out by the researchers. The same number of the classes also were video recorded ninety minutes per session. All the switch instances were transcribed. Furthermore, stimulated recalls have been conducted with the teachers separately to find out their perceptions on their own code-switching practices. The teachers were requested to write down their answers to the structured interview questions (Appendix 2). Their reports were subsequently transcribed and analyzed by the researchers. 


\section{Research Results}

As mentioned earlier, four teachers' classrooms were observed based on the observation protocol (Appendix 1). Table 1 tabulates the result of the taken observations.

\section{Table 1}

Distribution of the Observed Code-Switching Practices Through Observational Protocol

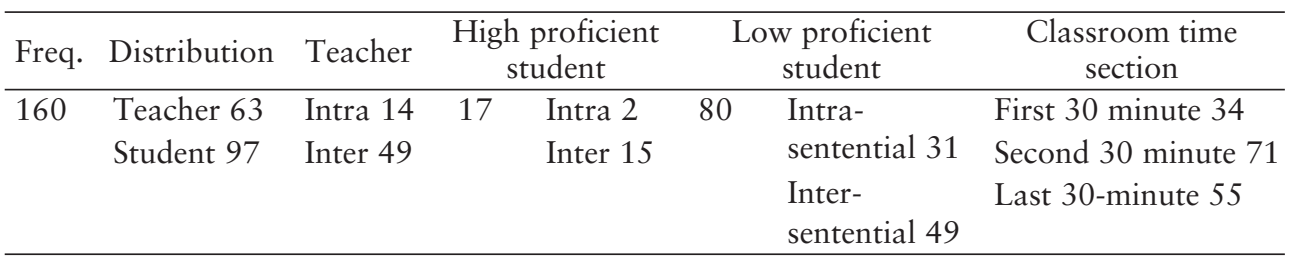

As apparent in Table 1, from all one hundred and sixty code-switching instances, sixty-three cases were practised by the teachers and ninety-seven instances practised by the students. Out of sixty-three instances practised by all the teachers, fourteen of them were intra-sentential and forty-nine cases were inter-sentential. Out of ninety-seven code-switching instances practised by the students, seventeen instances were practised by highly proficient students (two instances were intra-sentential and fifteen instances were inter-sentential).

As indicated already, four teachers' classrooms were video recorded to find out the teachers' possible code-switching practices in the process of their teachings. Tables 2 and 3 presents the results of the transcriptions and analysis of the data:

\section{Table 2}

Distribution of the Observed Code-Switching Practices Through Video-Shooting

\begin{tabular}{lllll}
\hline Frequency & Distribution & Teacher & \multicolumn{1}{c}{ Student } & \multicolumn{1}{c}{ Time } \\
\hline 61 & Teacher 23 & Intra-sentential 9 & Intra-sentential 18 & First 30 minute 21 \\
& Student 38 & Inter-sentential 14 & Inter-sentential 20 & Second 30 minute 22 \\
& & & & Last 30 minute 18 \\
\hline
\end{tabular}

Table 3

Reasons for Teachers' Code-Switching Practices

\begin{tabular}{|c|c|c|c|c|}
\hline \multirow[b]{2}{*}{$\begin{array}{l}\text { Reasons for } \\
\text { code-switching }\end{array}$} & Lack of proficiency & \multicolumn{2}{|c|}{ Classroom management } & \multirow[b]{2}{*}{ Solidarity } \\
\hline & $\begin{array}{c}\text { Lack of } \\
\text { proficiency \& } \\
\text { new vocabulary }\end{array}$ & Management & $\begin{array}{c}\text { Issues not } \\
\text { directly related } \\
\text { to teaching } \\
\end{array}$ & \\
\hline 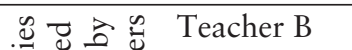 & 0 & 0 & 0 & 0 \\
\hline Teacher $\mathrm{CH}$ & 5 & 2 & 0 & 0 \\
\hline 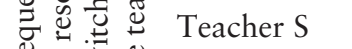 & 4 & 2 & 2 & 0 \\
\hline 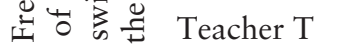 & 5 & 0 & 1 & 2 \\
\hline Total & 14 & 4 & 3 & 2 \\
\hline
\end{tabular}


Table 2 and 3 indicate that students' code-switching practices outnumber teachers' practices. Furthermore, one can observe that the main reason for teachers' code-switching was due to the conceived students' lack of linguistic proficiency.

Moreover, teachers' written responses to the structured interview protocol questions (Appendix 2) were analyzed qualitatively. Based on the analysis, the following main themes emerged on the teachers' practice of code-switching:

Theme 1: Type of code-switching (Intra-sentential - Inter-sentential).

Based on the analysis of the written interview data, teachers practiced intra-sentential - inter-sentential kinds of code-switching often during the second thirty-minute section of the classroom time. Indeed, one of the participating teachers commented that "I commonly resort to code-switching both in second and last $30 \mathrm{~min}$ sections of classroom time - because they are usually times to teach new grammar and doing workshops in my lesson plans." (Code: $\mathrm{CH} 11)$

Theme 2: Code-switching and language skills (Teaching reading skill).

Teachers often practiced code-switching while they were teaching vocabulary. "I usually do code-switch more in grammar teaching sections and reading activities because of new words and expressions" said one of the teachers. (Code: T 11)

Theme 3: Main motive for teachers' code-switching practice (Lack of proficiency of the students - Solidarity).

Most of the participating teachers claimed that the main reasons for them resorting to code-switching were lack of linguistic proficiency of the students and maintaining solidarity with their students. While asked about his main reason for classroom codeswitching, one of the teachers commented that:

"I have to switch my code first because in some cases students have not enough proficiency and I have to expend so much time to make them comprehend the new material by using other techniques such as Total Physical Response, so I find it better and time saving to switch my code." (Lack of proficiency) "My other reason to do code-switching is the need to have friendly relationship with some of the students." (Code: S 11)

\section{Conclusion}

Acknowledging the fact that professional development should take into account teachers' current instructional practices (Yenen \& Yontem, 2020), the present study aimed at exploring EFL teachers' code-switching practices. All the switches practised by teachers and students were from English to Persian. Students practised code-switching more than the teachers, in particular some of the teachers practised code-switching while responding to their students' questions. Both the teachers and the students resorted to code-switching during the second thirty-minute section of classroom time. Lower proficient students practiced more code-switching cases compared with higher proficient ones. Teachers practised code-switching in intra-sentential and inter-sentential types during activities such as discussing classroom management rules, teaching new vocabulary and teaching new grammatical items. Lack of students' linguistic proficiency, maintaining classroom management and also keeping solidarity with students were found to be the reasons of teachers' classroom code-switching practices. 
Some of the findings of the present research are consistent with the outcomes of the study conducted by Rezvani (2011) who reported that inter-sentential code-switching far outweighed the intra-sentential switching. Furthermore, Promnath and Tayjasanant (2016) reported "extra sentential" and "code selection" as two other types that were used by the teachers in addition to intra-sentential and inter-sentential types. They also reported that inter-sentential type was the most salient among the four code-switching types.

In line with the findings of the present study, Bilgin (2016) reported that teachers usually tended to practice code-switching while they were teaching grammar. However, Ahmad (2009) indicated that code-switching was used widely to perform diverse functions namely: checking for understanding, explaining difficult concepts, explaining the meaning of new words, elaborating on matters pertaining to classroom management, making the learners feel relaxed, providing explanations on grammatical aspects, establishing contacts with the learners and giving instructions to complete the tasks. In the same vein, Rezvani (2011) revealed the functions of code-switching as: giving instructions, doing translation, praising and encouraging students, correcting and explaining rules and maintaining classroom discipline. Similarly, Ibrahim (2013) and Nabifar (2017) in their studies came to the conclusion that teachers opted for code-switching in their classrooms mainly for lack of proficiency, managing classrooms, checking students' understanding, providing further explanations and socializing with students.

All in all, the results of the present study indicated that EFL teachers resorted to inter-sentential and intra-sentential types of code-switching in their classrooms mainly in teaching the grammar section of their text-books. The main motives for switching their codes in the classrooms were lack of students' proficiency, classroom management and showing solidarity with their students.

We have to be cognizant of the fact that the findings of the present study have to be interpreted in the light of its limitations. In particular, the number and gender of the participant teachers were not taken into account in the study. As indicated before, out of four participants only one of them was male. Thus, as it is commonly the case with most of the qualitative studies, the findings, understandably, cannot be generalized to the code-switching practices of all teachers. Thus, future studies could fruitfully explore this issue further by focusing on students' perceptions on their teachers' code-switching. Furthermore, conducting experimental researches on the effect of code-switching on students' learning different language skills would hopefully shed further light on the importance of code-switching in language learning and teaching.

\section{References}

Ahmad, B. H., \& Jusoff, K. (2009). Teachers' code-switching in classroom instructions for low English proficient learners. English Language Teaching, 2(2), 49-55.

Alhourani, A. Q. (2018). Code switching as a communicative strategy for the bilingual Saudi speakers at Jouf University. Online Submission, 1(4), 10-19.

Bhatti, A. (2018). Code-switching: A useful foreign language teaching tool in EFL classrooms. English Language Teaching, 11(6), 93-101.

Bilgin, S. S. (2016). Code switching in English language teaching (ELT) teaching practice in Turkey: Student teacher practices, beliefs and identity. Educational Research and Reviews, 11(8), 686-702. 
Bista, K. (2010). Factors of code switching among bilingual English students in the university classroom: A survey. Online Submission, 9(29), 1-19.

Gal, S. (1988). The political economy of code choice. Codeswitching: Anthropological and sociolinguistic perspectives, 48, 245-64.

Heasly, B., Lindner, J., Iliško, Dz., \& Salīte, I. (2020). From initiatives, to insights, to implementation of the sustainability and securitability agenda for 2030. Discourse and Communication for Sustainable Education, 11(1), 1-4. doi: 10.2478/dcse2020-0001

Ibrahim, E. H. E., Shah, M. I. A., \& Armia, N. T. (2013). Code-switching in English as a foreign language classroom: Teachers' attitudes. English Language Teaching, 6(7), 139-150.

Jodoin, J., \& Singer, J. (2020). Mainstreaming education for sustainable development in English as a foreign language: An analysis of the image-text interplay found in EFL textbooks in Japanese higher education. In W. L. Filho, A. L. Salvia, R.W. Pretorius, L. L. Brandli, E. Manolas, F. Alves, U. Azeiteiro, J. Rogers, C. Shiel, \& A. DoPaco (Eds.), Universities as living labs for sustainable development (pp. 545565). Cham, Springer.

Kapranov, O. (2021). Discursive representations of education for sustainable development in policy documents by English medium instruction schools in Estonia and Norway. Discourse and Communication for Sustainable Education, 12(1), 1, 55-66.

Manteaw, B. O. (2020). Education and learning in sustainable development: Foregrounding an emergent discourse. Discourse and Communication for Sustainable Education, 11(2), 5-19.

Moghadam, R. N., \& Davoudi, M. (2016). The relationship between Iranian EFL University professors' code switching and their characteristics such as age, gender and educational levels. Journal of Studies in Education, 6(1), 74-88.

Muysken, P. (2011). Code-switching. In R. Mesthrie, (Ed.), The Cambridge handbook of sociolinguistics (pp. 301-314). Cambridge: Cambridge University Press.

Nabifar, N., \& Khalilzad, M. (2017). The effect of code switching on the acquisition of object relative clauses by Iranian EFL learners. Journal of Studies in Learning and Teaching English, 6(1), 89-112.

Nunan, D., \& Bailey, K. M. (2009). Exploring second language classroom research: A comprehensive guide. Boston: Heinle, Cengage Learning.

Promnath, K., \& Tayjasanant, C. (2016). English-Thai code-switching of teachers in ESP classes. PASAA: Journal of Language Teaching and Learning in Thailand, 51, 97-126.

Rezvani, E., Street, H. J., \& Rasekh, A. E. (2011). Code-switching in Iranian elementary EFL classrooms: An exploratory investigation. English language teaching, 4(1), $18-25$.

Salīte, I., Gedžūne, I., \& Gedžūne, I. (2009). Educational action research for sustainability: Seeking wisdom of insight in teacher education. Journal of Teacher Education for Sustainability, 11(2), 14-30.

Songxaba, S. L., Coetzer, A., \& Molepo, J. M. (2017). Perceptions of teachers on creating space for code switching as a teaching strategy in second language teaching in the Eastern Cape province, South Africa. Reading \& Writing, 8(1), 1-7.

Then, D. C. O., \& Ting, S. H. (2009). A preliminary study of teacher code-switching in secondary English and science in Malaysia. Tesl-Ej, 13(1), 1-17. 
Wardhaugh, R. (2010). An introduction to sociolinguistics (6 ${ }^{\text {th }} \mathrm{Ed}$.). London: WileyBlackwell.

Yeganepoor, P., \& Seifoori, Z. Z. (2013). The impact of code-switching on bilingual EFL learners' reading comprehension. Journal of English Language Pedagogy and Practice, 6(13), 167-179.

Yenen, E. T., \& Yontem, M. K. (2020). Teachers’ professional development needs: A Q method analysis. Discourse and Communication for Sustainable Education, 11(2), 159-176.

Zygmunt, T. (2016). Language education for sustainable development. Discourse and Communication for Sustainable Education, 7(1), 112-124.

Correspondence concerning this paper should be addressed to Dr. Alireza Bonyadi, English Department, Faculty of Humanities, Urmia Branch Islamic Azad University, Urmia, Iran. Email: a.bonyadi@iaurmia.ac.ir

\section{Appendix 1}

Sample of the manual observation protocol

\begin{tabular}{llr}
\hline \multicolumn{1}{c}{ Phenomenon } & \multicolumn{1}{c}{ Quality of existence } \\
\hline Occurrence of C-S in the classroom & Yes & $\square$ \\
\hline Time of C-S occurrence in classroom & No & $\square$ \\
& Sirst 30 min & $\square$ \\
& Lecond 30 min 30 min & $\square$ \\
\hline C-S performer & Teacher & $\square$ \\
& High Proficient Student & $\square$ \\
& Low Proficient Student & $\square$ \\
\hline Type of C-S employed & Intra-sentential & $\square$ \\
& Inter-sentential & $\square$ \\
\hline Activities in which C-S happened & Listening & $\square$ \\
& Speaking & $\square$ \\
& Reading & $\square$ \\
& Writing & $\square$ \\
& Grammar Teaching & $\square$ \\
& Checking Homework & $\square$ \\
& Workshop & $\square$ \\
& Announcing Class Rules & $\square$ \\
& How to study & $\square$ \\
\hline
\end{tabular}


Appendix 2

Sample of the structured interview protocol

Teacher's name:

Researcher's name:

Date:

1 - Do you practice code-switching while teaching in the classrooms?

2 - Which language do you usually switch to?

3 - What types of code-switching are you practicing in classrooms?

4 - During which period of classroom time you usually practice code-switching: first $30 \mathrm{~min}$, second $30 \mathrm{~min}$ or last $30 \mathrm{~min}$ ?

5 - In which activities do you usually practice code-switching more?

6 - Why do you resort to code-switching in classrooms? 